\title{
ISPARTA KILIÇ ÖREN MEVKIIINDE BİR KAÇAK KAZI ALANINDA ELEKTRİK ÖZDİRENÇ TOMOGRAFİ ARAŞTIRMASI
}

\author{
Sedat YILMAZ1,*, Erdinç ÖKSÜM1 ${ }^{1}$, Olcay ÇAKMAK² \\ ${ }^{1}$ Süleyman Demirel Üniversitesi, Mühendislik Fakültesi, Jeofizik Mühendisliği Bölümü, Isparta, Türkiye \\ 2 Süleyman Demirel Üniversitesi, Deprem ve Jeoteknik Araştırma Merkezi, Isparta, Türkiye
}

\begin{tabular}{ll}
\hline Anahtar Kelimeler & Öz \\
\hline Özdirenç, & Isparta Kılıç Ören mevkiinde kaçak kazı sonucu Roma dönemi mimarisine ait olduğu \\
Tomografi, & düşünülen gömülü anıtsal bir kalıntı ortaya çıkmıștır. Bu kalıntının sürekliliğini ve \\
Modelleme, & kazı etrafında gömülü olası kalıntıları belirlemek için iki bölgede toplam 20 profilde \\
Arkeoloji, & Wenner-Schlumberger dizilimine göre elektrik özdirenç tomografi ölçümleri \\
Isparta. & gerçekleştirilmiştir. Ölçülen saha verilerini değerlendirmede kullanılan yazılım iki \\
& farklı ters çözüm yöntemi seçeneği sunmaktadır. Bu iki yöntemin yeterliliği yaygın \\
& elektrot dizilimleri için sentetik arkeolojik modeller kullanılarak test edilmiştir. \\
& Kullanılan arkeolojik modeller (blok ve yatay silindir), gömülü yapı kalıntılarına \\
& karşılı gelen duvarları ve sütunları temsil etmektedir. Sentetik model sonuçları, \\
& arkeoloji sahasından ölçülen özdirenç verilerin yorumlanmasina katkılar \\
& sağlamıştır. \\
\hline
\end{tabular}

\section{ELECTRICAL RESISTIVITY TOMOGRAPHY SURVEY IN AN ILLEGAL EXCAVATION SITE AT ISPARTA KILIÇ ÖREN}

Keywords
Resistivity,
Tomography,
Modeling,
Archaeology,
Isparta.

Alıntı / Cite

Yılmaz, S., Öksüm, E., Çakmak, O., (2019). Isparta Kılıç Ören Mevkiinde Bir Kaçak Kazı Alanında Elektrik Özdirenç Tomografi Araştırması, Mühendislik Bilimleri ve Tasarım Dergisi, 7(1), 46-51.

\begin{abstract}
An illegal excavation at Kılıç Öreniçi site revealed a monumental ruin that was thought to belong to Roman period architecture. To determine the continuity of these historical remains and other possible buried remains around the excavation, electrical resistivity tomography measurements were performed according to the Wenner-Schlumberger array in a total of twenty lines in two areas. The software used to evaluate the measured field data offers two different inversion methods. The ability of these two methods has been tested for common electrode arrays using synthetic archaeological models. The used archaeological models (block and horizontal cylinder) represent walls and columns corresponding to the remains of buried foundation. The modeling results provided contributions to the interpretation of the resistivity data measured from archaeology field.
\end{abstract}

\begin{tabular}{l|l|l}
\hline Yazar Kimliği / Author ID (ORCID Number) & Makale Süreci / Article Process \\
\hline S. Yllmaz, 0000-0002-9841-4900 & Başvuru Tarihi / Submission Date & 17.05 .2018 \\
E. Öksüm, 0000-0001-8386-9411 & Revizyon Tarihi / Revision Date & 09.10 .2018 \\
O. Çakmak, 0000-0003-4282-4481 & Kabul Tarihi / Accepted Date & 06.11 .2018 \\
& Yayım Tarihi / Published Date & 25.03 .2019 \\
\hline
\end{tabular}

\section{Giriş}

Elektrik özdirenç yöntemi en yaygın kullanılan jeofizik ölçüm tekniklerinden biridir. Bu yöntem, yeraltı suyu ve maden araştırmaları, jeoteknik ve çevre araştırmaları ve arkeolojik çalışmalar gibi çok çeşitli
* ilgili yazar / Corresponding author: sedatyilmaz@sdu.edu.tr, +90-246-211-1349 alanlarda uygulanabilir (örn. Atekwana vd., 2000; Bayrak ve Senel, 2012; Anudu vd., 2014; Yilmaz ve Narman, 2015; Karavul vd., 2016; Yilmaz ve Koksoy, 2017). Elektrik özdirenç yüzey araştırmalarının amacı, yer yüzeyinde ölçüm yaparak yer altı özdirenç değişimlerini belirlemektir ve bu da yeraltı 
malzemelerin elektriksel belirtileri ile sonuçlanmaktadır. Elektrik özdirenç tomografi (ERT) yeraltı özdirenç kesitlerinin doğru iki-boyutlu (2-B) sayısal özdirenç modellerini oluşturmak için geliştirilmiştir (örn. Loke ve Barker, 1996; Dahlin ve Loke, 1998). Tüm özdirenç araştırmalarında elektrot dizilimi, çözünürlüğün ve araştırma derinliğinin belirlenmesinde önemli bir rol oynar. Schlumberger, Wenner, dipol-dipol, pol-dipol vd. gibi farklı elektrot dizilimleri 1920'lerden günümüze değin geliștirilmesine rağmen, bunların her birinin kendine özgü değerleri ve dezavantajları vardır. Literatürde bazı makaleler, belirli hedefler üzerinde iki veya daha fazla elektrot dizilimi arasındaki çözünürlüğün veya duyarlılığın sayısal karşılaștırması üzerinedir (örn. Dahlin ve Zhou, 2004; Henning vd., 2005; Nordiana vd., 2014).

Arkeojeofizik araştırmalar, yeraltında gömülü kalıntıların yeri, biçimi, uzanımı ve derinliği hakkında bilgi vermekte ve arkeolojik kazıların planlanması ve yürütülmesi aşamasında katkı sağlamaktadır. Buna bağlı olarak, arkeolojik kazıların maliyeti, süresi ve kazı sırasında antik yapı kalıntısının görebileceği olası hasarlar azalacaktır. Arkeolojik yapılar, boşluklar, mezarlar ve taş duvarlar içinde bulundukları ortamdan daha yüksek özdirenç sergiledikleri için, bu yapıların araştırılmasında özdirenç yöntemi öncelikle tercih edilmektedir (örn. Griffiths ve Barker, 1994; Tsokas vd., 1994; Osella vd., 2004; Papadopoulos vd., 2007; Tsokas vd., 2008).

$\mathrm{Bu}$ çalışmada, Kılıç köyü Ören mevkiindeki kazı etrafında gömülü kalıntıların varlığını ve sürekliliğini belirlemek için ERT yöntemiyle araştırma yapılmıştır. Saha verilerini yorumlamaya katkı sağlaması için, bu arkeolojik alanda gömülü olduğu düșünülen kalıntılara karşılık gelen sentetik modelleri (yatay silindir ve blok) kullanarak bir dizi testler yapılmıştır.

\section{2. Çalışma Alanı ve Kısa Arkeolojisi}

Çalışma alanı Isparta ilinin $41 \mathrm{~km}$ kuzeybatısında Burdur gölü kuzeyinde Kılıç köyünün yaklaşık 1.5 km kuzeyinde Ören mevkiindedir (Şekil 1a). Bu bölgede ovanın büyük bir kısmına yayılmış olan yüzey verileri ve seramik yoğunluğu güçlü bir yerleşimin varlığına işaret etmektedir (Özsait 2011). Bölgede yapılan kaçak kazılar ile Roma Dönemi'ne ait olduğu düşünülen anıtsal bir yapıya ait mimari bloklar (10 adet mimari parça ve bir adet onur yazıtı) ortaya çıkmıştır (Şekil 1b). Bunlardan biri $80 \mathrm{~cm}$ çapında boyu bilinemeyen sütun parçası, kireçtaşından 26 yivli monoblok olarak işlenmiştir. Bir diğeri ise arşitrav köşe bloğu, aslan çörtenli yumurta dizisi ve rozet bulunan yarısı toprak altında olan ve sütunla aynı dizide yer alır (Özsait, 2011). Bu ve önceki çalışmalardan (Robert, 1948; Özsait 1980) elde edilen arkeolojik bulgular, Pisidya bölgesi Baris antik kentinin Kılıç köyü sınırlarında olduğu tahmin edilmektedir. Antik dönemde Pisidya sınırları içerisinde yer alan Kılıç köyü ve yakınında birkaç höyük ve tunç çağına ait oda mezarları farklı yıllardaki arkeolojik araştırmalardan tespit edilmiștir. Kılıç köyü içindeki çeşme inşaatında kullanılmış olan Roma Dönemi mimari parçaları, Isparta müzesine nakledilen kapaksız lahit ve Yunanca kitabe dışında köy yakınında kayaya oyulmuş tekne ve oda mezarların bulunmasından bir kent kalıntısının civarda olduğunu gösteren eşsiz buluntulardır.

(a)

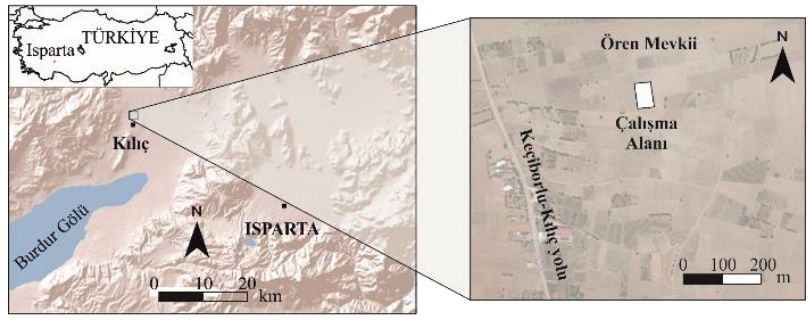

(b)
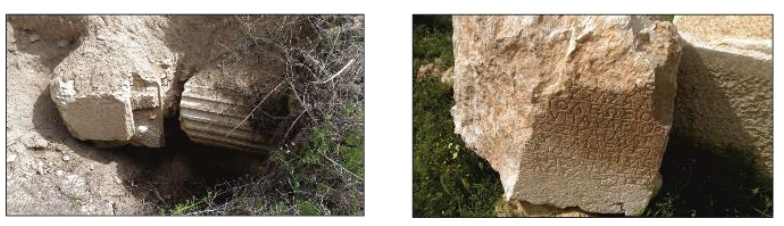

Şekil 1. Çalışma alanı konumu (a) ve kaçak kazı ile ortaya çıkmıș mimari kalıntılar (b).

\section{Sentetik ERT Model Testi}

Yatay sütun ve olası duvar kalıntılarına karşılık gelen arkeolojik modeller (yatay silindir ve blok) için, muhtelif elektrot dizilimlerine (dipol-dipol, pol-dipol, pol-pol, Wenner ve Wenner-Schlumberger) göre bir dizi model testi yapılmıștır. Sentetik modellerden hesaplanan görünür özdirenç verilerin ters çözümleri yapılarak farklı dizilim tepkileri karşılaştırılmıştır. Tüm modellerde düz çözümler Res2Dmod ücretsiz yazılım uygulaması ile gerçekleştirilmiştir. Sentetik model verilerin ters çözümlerinde ise Res2Dinv (Loke ve Barker, 1996) yazılımı kullanılmıştır. Bu yazılım, sahada ölçülen veriler ile model verileri arasındaki farkları en küçüklemek için düzgünlük-kısıtlı enküçük kareler ve robust ters çözüm yöntemlerinin kullanılmasına olanak sağlamaktadır. Sentetik arkeolojik modeller için bu iki ters çözüm yönteminin sonuçları dizilimlere göre irdelenmiştir. 


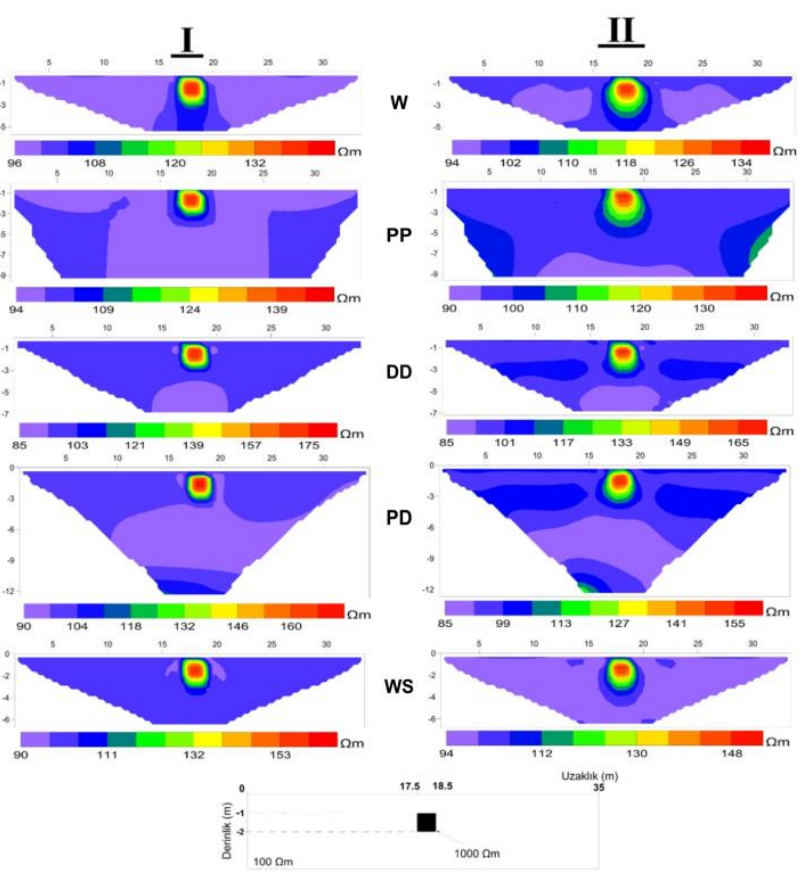

Şekil 2. Tek bloktan oluşan arkeolojik modelin ERT kesitlerini karşılaştırma (I: robust ters çözüm; II: düzgünlük-kısıtlı en-küçük kareler ters çözüm). W:

Wenner, PP: pol-pol, DD: dipol-dipol, PD: pol-dipol ve WS: Wenner-Schlumberger.

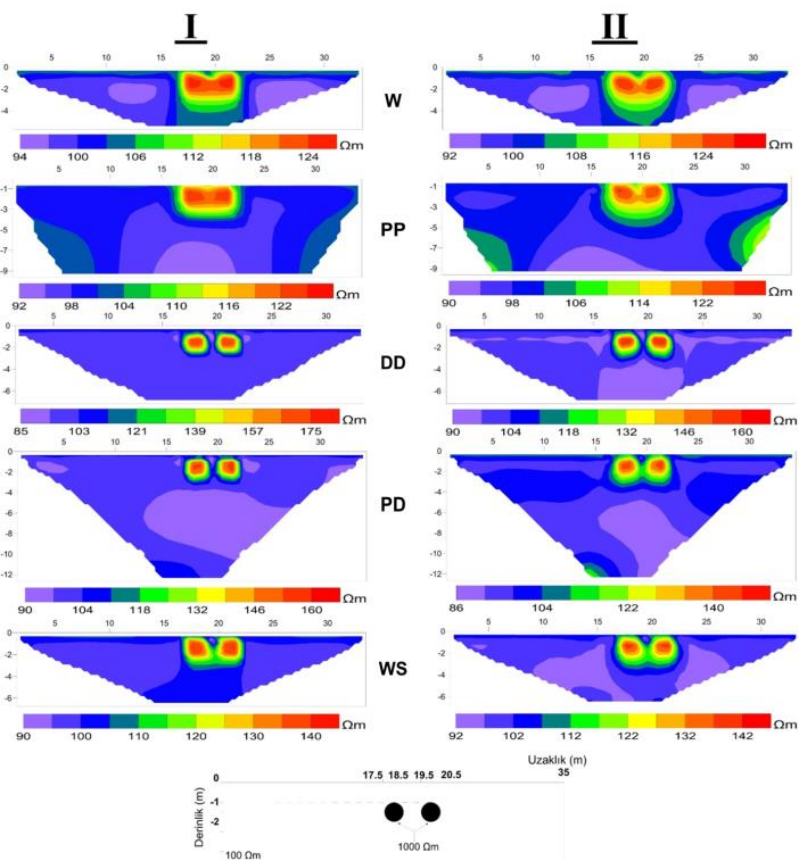

Șekil 3. İki yatay silindirden olușan arkeolojik modelin ERT kesitlerini karşılaștırma (I: robust ters çözüm; II: düzgünlük-kısıtlı en-küçük kareler ters çözüm). W: Wenner, PP: pol-pol, DD: dipol-dipol, PD: pol-dipol ve WS: Wenner-Schlumberger.
Birinci model tek bloktan oluşmakta ve özdirenci 1000 $\Omega \mathrm{m}$ olup çevre ortam özdirenci $100 \Omega \mathrm{m}$ ve yüzeyden 1 m derinlikte $1 \times 1 \mathrm{~m}$ boyutlarındadır. ERT kesitleri Şekil 2'de verilmektedir. İkinci model ise $2 \mathrm{~m}$ aralıklı iki yatay silindirden oluşmakta ve yatay silindirlerin ve çevre ortam özdirençleri sırasıyla $1000 \Omega \mathrm{m}$ ve 100 $\Omega \mathrm{m}$ kadardır. Her bir yatay silindir yüzeyden $1 \mathrm{~m}$ derinlikte ve $1 \times 1 \mathrm{~m}$ boyutlarındadır ve ERT kesitleri Şekil 3'te verilmektedir. Tüm ters çözümler 5 yineleme sonunda $\% 0.18$ ile $\% 0.29$ arasında değissen hata değerlerine sahiptir. Arkeolojik kalıntılar yüksek dirençli yapılar olduğu için, onlar elektrik özdirenç görüntülerde yüksek özdirenç belirtiler olarak görülürler. Model tepkilerin ters çözümlerinden elde edilen ERT kesitlerinde özdirenç değişimleri 85-180 $\Omega \mathrm{m}$ aralığındadır. Her iki ters çözüm yöntemi de tek blok modelini iyi yansıtmakta, fakat robust ters çözüm yapı kenarlarını daha düzgün vermektedir (Şekil 2). Diğer taraftan, özdirenç kesitlerinde iki yakın yatay silindirin birbirinden ayırt edilebilmesini dipol-dipol, pol-dipol, Wenner-Schlumberger dizilimleri diğerlerine göre daha iyi sağlamaktadır (Șekil 3).

\section{Saha ERT Araştırması}

ERT ölçümleri kaçak kazı alanı batısında ve kuzeyinde iki ayrı alanda 48 elektrotlu çok-kanallı bir özdirenç cihazı (GF Instruments, Çek Cumhuriyeti) kullanılarak gerçekleștirilmiștir. "A" alanı içinde 9 ERT profili var iken, "B" alanı içinde ise 11 ERT profili vardır (Sekil 4). Profiller arası $1 \mathrm{~m}$ olup, tüm ölçümler WennerSchlumberger elektrot dizilimine göre $1 \mathrm{~m}$ birim elektrot aralığına göre yapılmıștır. Sentetik modelleme sonuçlarına göre birkaç dizilim yapıların ayırt edilmesinde başarılı sonuç vermiștir. Ancak Wenner-Schlumberger dizilimi, derinlikle özdirenç farklılıklarına daha duyarlı (Dahlin and Zhou, 2004) olduğu için tercih edilmiştir. Saha görünür özdirenç verilerinin değerlendirmesinde ise Res2Dinv yazılımının robust ters çözüm seçeneği kullanılmıștır. Çalışma alanının iki sahasından elde edilen 20 adet ERT (ERT-1A-9A ve ERT-1B-11B) kesitleri sirasiyla Şekil 5 ve Şekil 6'da verilmiștir. Elde edilen bu kesitler ile $8 \mathrm{~m}$ derinliğe kadar olan özdirenç dağılımı gözlenmiștir. "A" alanının kaçak kazı bölgesine en yakın olan ERT-1A kesitinde yüksek özdirenç değerleri $(>150 \Omega \mathrm{m})$ profilin 12 . metresi ve 19 . metrelerinde görülmektedir (Şekil 5). Gözlemsel olarak kaçak kazı sonucu görülen sütun yapısının yeraltındaki devamı yaklaşık olarak bu profilin 13-14 metreleri arasında yer almaktadır. Dolayısıyla kesitin bu mesafesinde $1.4 \mathrm{~m}$ derinliğinde görülen yüksek özdirenç değeri, söz konusu bu sütun yapısından ileri gelmektedir. Buna göre aynı profilin 17-18 m uzaklıklarında görülen yine yüksek özdirenç değerleri, profilin bu konumunda da benzer malzemeden kaynaklı farklı bir kalıntının varlı̆̆ını göstermektedir. Kesitin 20-30 m yatay uzaklığında kısmen yüksek özdirenç $(\sim 110 \Omega \mathrm{m})$ belirtinin görüldüğü yerler yine muhtemel yapı kalıntılarından ileri gelmektedir. 


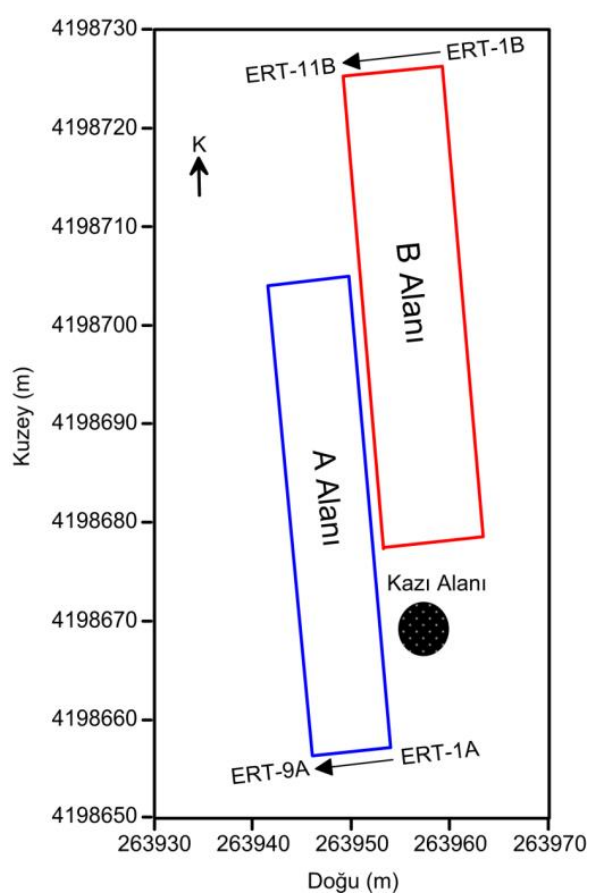

Şekil 4. Çalışma alanındaki ERT profillerinin konumu.

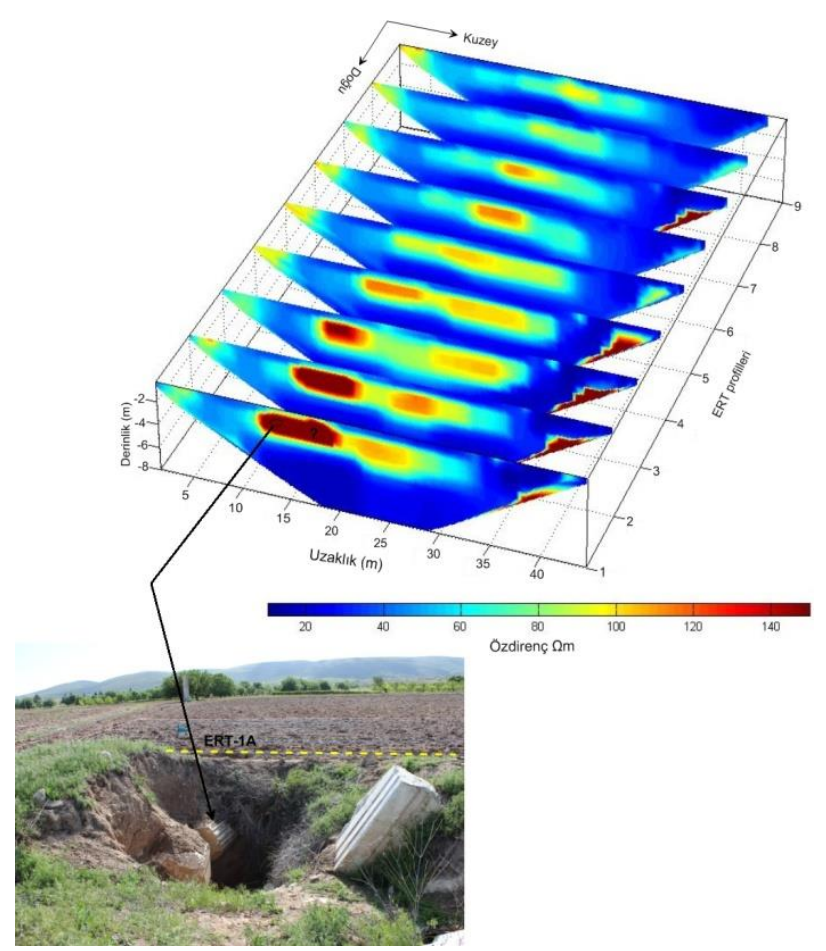

Şekil 5. "A" alanında 9 profil boyunca 2-B ERT kesitlerin birleștirilmiş görüntüsü.

ERT-1A profilinde olduğu gibi ERT-2A ve ERT-3A kesitlerinde de yatay sütundan kaynaklanan belirtiler görülmektedir. Tüm kesitlerin orta kısımlarında görülen özdirenç $(\sim 110 \Omega \mathrm{m})$ belirtiler batı doğrultusunda azalım göstermektedir. Ayrıca tüm profillerin başlangıcındaki kısmen yüksek özdirenç $(\sim 90 \Omega \mathrm{m})$ belirtiler ise yine yer altında gömülü kalıntıları işaret etmektedir. Kesitlerde düșük özdirenç $(<30 \Omega \mathrm{m})$ belirtiler ise, arkeolojik yapı kalıntıların olmadığı bölgelere karşılık gelmektedir. "B" alanına ait tüm kesitlerin (ERT-1B-11B) birleşik görüntüsü Şekil 6'da gösterilmiștir. Buna göre kesitlerin başlangıcında yüksek özdirence $(>150 \Omega \mathrm{m})$ sahip bir bölge görülmektedir ve dolayısıyla önemli bir gömülü arkeolojik yapının varlığına ișaret etmektedir. Diğer taraftan yine tüm kesitlerde yaklaşık $45 \mathrm{~m}$ yatay uzaklığında kısmen yüksek özdirence $(\sim 85 \Omega \mathrm{m})$ sahip bir bölge ise, bu alandaki diğer yapı kalıntısının varlığını göstermektedir. $\mathrm{Bu}$ yüksek özdirenç belirti, sentetik blok model için elde edilen sonuçlar dikkate alındığında muhtemel bir duvar kalıntısına karşıllk gelmektedir. Özdirencin ortalama $30 \Omega \mathrm{m}$ ve daha düşük olduğu bölgelerde ise herhangi bir arkeolojik kalıntı yoktur.

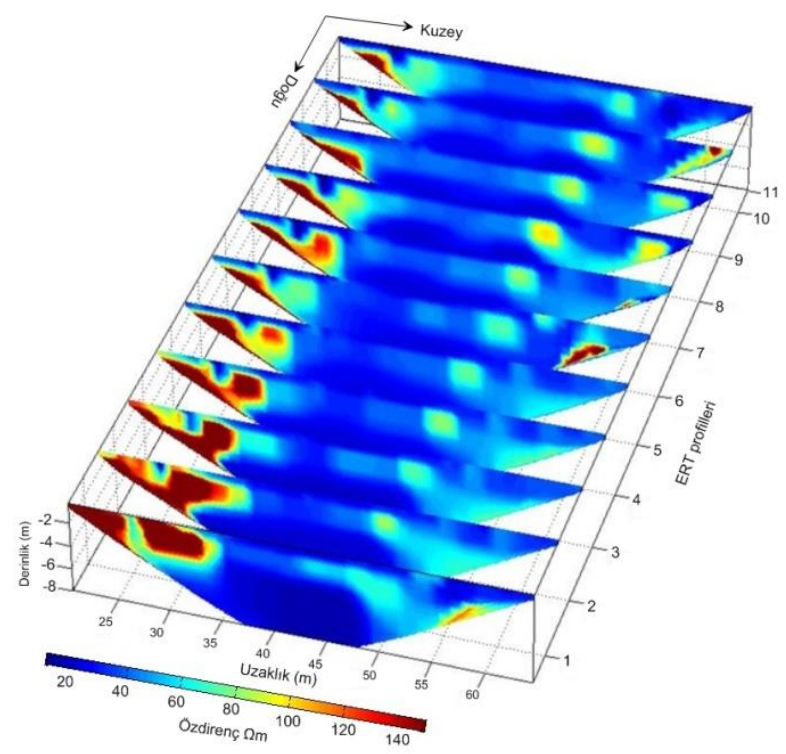

Şekil 6. “B” alanında 11 profil boyunca 2-B ERT kesitlerin birleștirilmiș görüntüsü.

Birbirine paralel doğrultuda olan 2-B ERT profillerinin birleştirilmesiyle farklı derinliklere ait özdirenç kat haritaları elde edilir. Bu șekilde bir gösterim muhtemel yapı belirtilerinin yaklașı üç-boyutlu resmini ortaya koymaktadır. Bu amaçla, ERT verileri birleştirilmiş ve belirti yoğunluğu fazla olan derinlikler için özdirenç kat haritaları $(0.77 \mathrm{~m}, 1.35 \mathrm{~m}$, $1.99 \mathrm{~m}, 2.69 \mathrm{~m}$ ve $3.46 \mathrm{~m}$ derinlikleri için) çizilmiştir (Şekil 7). Buna göre, $0.77 \mathrm{~m}$ ile $2.69 \mathrm{~m}$ derinlikleri arasında görülen yüksek özdirenç belirtiler, kaçak kazı neticesiyle bilinen sütun yapısı ve hemen kuzeyinde yer alan olası diğer bir arkeolojik yapıdan ileri gelmektedir (Şekil 7a). Diğer taraftan, 0.77 m-1.35 m derinlik aralığında kesitlerin güneyinde ve $1.35 \mathrm{~m}$ $2.69 \mathrm{~m}$ derinliklerinde kesitlerin orta kesimlerinde görülen kısmen yüksek özdirenç $(\sim 110 \Omega \mathrm{m})$ belirtiler ise, muhtemel yapı kalıntılarının yatay düzlemdeki dağılımlarını göstermektedir. "B" alanına ait özdirenç kat haritalarının güneyindeki yüksek özdirenç $(>150$ $\Omega \mathrm{m}$ ) belirtiler, doğu yönünde yüzeye çok yakın olan önemli bir arkeolojik yapı kalıntısının varlığını göstermektedir (Șekil 7b). Diğer taraftan kesitlerin 
ortasındaki kısmen yüksek özdirenç $(\sim 85 \Omega \mathrm{m})$ belirtiler ise, burada yer alan olası duvar kalıntısının 1.35 m-2.69 m arasında yer aldığını göstermektedir.

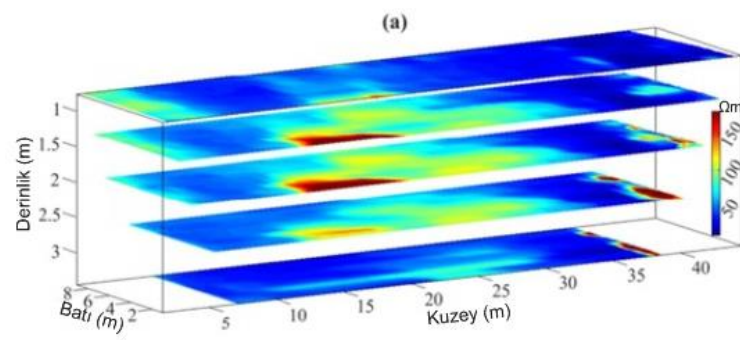

(b)

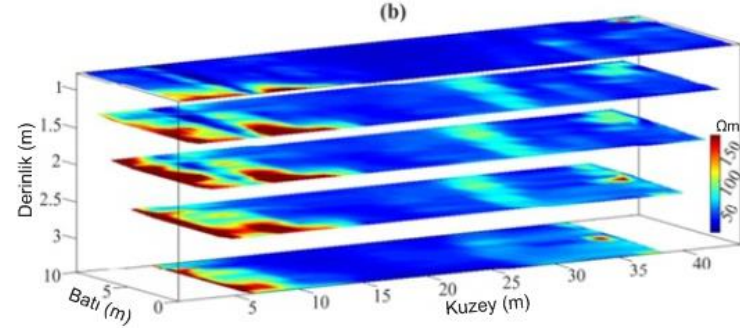

Şekil 7. Farklı derinliklere $(0.77 \mathrm{~m}, 1.35 \mathrm{~m}, 1.99 \mathrm{~m}$, 2.69 m, 3.46) ait özdirenç kat haritaları. (a) "A" alanı, (b) "B" alanı.

\section{Sonuç ve Tartışma}

Bu çalışmada, ERT yöntemi kullanılarak Kılıç köyü Ören mevkiinde kaçak kazı sonucu ortaya çıkmış yapıların devamlılığı ve gömülü diğer muhtemel kalıntıların varlığı araştırılmıştır. Ayrıca, saha verilerini yorumlamaya katkı sağlaması için, arkeolojik kalıntılara karşılık gelen yatay silindir ve blok gibi modeller için bir dizi sentetik testler yapılmıştır.

ERT yönteminde arkeolojik yapılar, doğal olarak çevre ortamınkine göre daha yüksek özdirenç belirtiler vermektedir. Ölçülen verilerin değerlendirme sonuçlarına göre, özdirenç kesitlerindeki özdirenç değişim $5 \Omega \mathrm{m}$ ile $400 \Omega \mathrm{m}$ arasındadır. Kaçak kazı sonucu ortaya çıkmış bilinen arkeolojik sütun yapısının uzanım doğrultusu A alanı içinde yer almaktadır. ERT-1-3 kesitlerinde 13-18 m yatay uzaklık aralığında görülen yüksek özdirenç (>150 $\Omega \mathrm{m})$ belirti kaçak kazı ile bir kısmı ortaya çıkmış yatay arkeolojik sütunun etkisini içermektedir. Sentetik ERT model test sonuçları dikkate alındığında, bu geniş özdirenç belirtinin sadece tek bir sütundan olmadığı açıktır. Dolayısıyla, kaçak kazı ile gözlenmiş sütunun yakınında ikinci bir sütun vardır. Aynı kesitte yaklaşık 20-30 m yatay uzaklığında kısmen daha düşük fakat ortalama özdirençlerden yine daha yüksek özdirenç (yaklaşık olarak $110 \Omega \mathrm{m}$ ) belirtinin görüldüğü yerler yine muhtemel yapı kalıntılarından ileri gelmektedir. Kaçak kazı alanının kuzeyinde ERT kesitlerinin başlangıcındaki yüksek özdirenç (>150 $\Omega \mathrm{m}$ ) belirti batıda derinde doğuda ise yüzeye daha yakın gömülü kalıntılara işaret etmektedir. Yine sentetik ERT model test sonuçları dikkate alındığında, kesitlerin ortasındaki kısmen yüksek özdirenç $(\sim 85 \Omega \mathrm{m})$ belirtinin gömülü duvar kalıntısından kaynaklandığı açlktır.

\section{Teşekkür}

Bu çalışma Süleyman Demirel Üniversitesi Bilimsel Araştırma Projeleri Koordinasyon Birimi tarafından 4896-M1-17 nolu proje kapsamında desteklenmiştir. Yazarlar, arkeo-jeofizik saha çalıșması izni için T.C. Kültür ve Turizm Bakanlığı Kültür Varlıkları ve Müzeler Genel Müdürlüğü'ne içtenlikle teşekkür eder. Yazarlar, Isparta Müzesi Müdürlüğün'den arkeolog Mustafa Akaslan'a ve sanat tarihçisi Murat Ak'a teşekkür borçludurlar ve ayrıca saha çalışmasına katkılarından dolayı Onur Doğan ve Erkan Tekelioğlu'na teşekkür ederler. Kullanılan jeofizik ekipman Süleyman Demirel Üniversitesi Deprem ve Jeoteknik Araştırma Merkezi tarafından sağlanmıştır ve Prof. Dr. Ümit Yalçın Kalyoncuoğlu' na teşekkürü bir borç biliriz.

\section{Conflict of Interest / Çıkar Çatışması}

Yazarlar tarafından herhangi bir çıkar çatışması beyan edilmemiştir.

No conflict of interest was declared by the authors.

\section{Kaynaklar}

Anudu, G.K., Essien, B.I, Obrike S..E., 2014. Hydrogeophysical investigation and estimation of groundwater potentials of the Lower Paleozoic to Precambrian crystalline basement rocks in Kefl area, north-central Nigeria, using resistivity methods. Arabian Journal of Geosciences, 7, 311322.

Atekwana, E.A., Sauck, W.A., Werkema, D.D., 2000. Investigations of geoelectrical signatures at a hydrocarbon contaminated site. Journal of Applied Geophysics, 44, 167-180.

Bayrak, M., Senel, L., 2012. Two-dimensional resistivity imaging in the Kestelek boron area by VLF and DC resistivity methods, Arabian Journal of Geosciences, 82, 1-10.

Dahlin, T., Loke, M.H., 1998. Resolution of 2D Wenner resistivity imaging as assessed by numerical modelling. Journal of Applied Geophysics, 38, 237 249.

Dahlin, T., Zhou, B., 2004. A numerical comparison of 2D resistivity imaging with 10 electrode arrays. Geophysical Prospecting, 52, 379-398.

Griffiths, D.H., Barker, R.D., 1994. Electrical Imaging in Archaeology. Journal of Archaeological Science, 21, 153-158. 
Henning, T., Weller, A., Canh, T., 2005. The effect of dike geometry on different resistivity configurations. Applied Geophysics, 57, 78-292.

Karavul, C., Karaaslan, H, Demirkol, A., 2016. Investigation of structures in the Alabanda Bouleuterion by electrical resistivity method. Arabian Journal of Geosciences, 9: 511.

Loke, M.H., Barker, R.D., 1996. Rapid least-squares inversion of apparent resistivity pseudosections by a quasi-newton method. Geophysical Prospecting, $44,131-152$.

Nordiana, M.M., Rosli, S., Nawawi, M.N.M., 2014. A numerical comparison of enhancing horizontal resolution (EHR) technique utilizing 2D resistivity imaging. Arabian Journal of Geosciences, 7, 299309.

Osella, A., de la Vega M., Lascano E., 2004. 3D electrical imaging of an archaeological site using electric and electromagnetic methods, Geophysics, 70, 101-107.

Özsait, M., 1980. İlk Çağ Tarihinde Pisidia, İstanbul, 16.

Özsait, M., 2011. Surveys in Burdur and Isparta in 2010. News of Archaeology from Anatolia's Mediterranean Areas (ANMED), 9, 164-173.

Robert, L., 1948. Deux Texes İnulitises Sur Perge et Side, Hellenica, 5, 64-69.

Tsokas, G.N., Giannopoulos, A., Tsourlos, P., Vargemezis, G., Tealby J.M., Sarris A., Papazachos C.B., 1994. A large scale geophysical survey in the archaeological site of Europos (Northern Greece). Journal of Applied Geophysics, 32, 85-98.

Tsokas, G.N., Tsourlos, P.I., Vargemezis, G., Novack, M., 2008. Nondestructive Electrical Resistivity Tomography for Indoor Investigation: the Case of Kapnikarea Church in Athens. Archaeological Prospection, 15, 47-61.

Papadopoulos, N.G., Tsourlos, P., Tsokas, G.N., Sarris, A., 2007. Efficient ERT measuring and inversion strategies for 3D imaging of buried antiquities: Near Surface Geophysics, 6, 349-362.

Yilmaz, S., Narman, C., 2015. 2-D electrical resistivity imaging for investigating an active landslide along a ridgeway in Burdur region, southern Turkey. Arabian Journal of Geosciences, 8, 3343-3349.

Yilmaz, S., Koksoy, M., 2017. Electrical resistivity imaging and dye tracer test for the estimation of water leakage paths from reservoir of Akdeğirmen Dam in Afyonkarahisar, Turkey. Environmental Earth Sciences, 76: 829. 